\title{
Short-Term Exposure to Bilirubin Reduces Synaptic Activation in Rat Transverse Hippocampal Slices
}

\author{
THOR WILLY RUUD HANSEN, OLE PAULSEN, LEIF GJERSTAD, AND DAG BRATLID
}

Neonatal Research Laboratory, Department of Pediatric Research, Department of Neurology, and Department of

Pediatrics, The National Hospital, University of Oslo, Norway

\begin{abstract}
We evaluated the feasibility of using the in vitro transverse rat hippocampal slice as a model to study the effect of bilirubin on neuronal activity. Bilirubin in concentrations from $100 \mu \mathrm{mol} /$ liter to $1 \mathrm{mmol} / \mathrm{liter}$ with bovine serum albumin as a stabilizer caused a significant decrease in the slope of the field excitatory postsynaptic potentials, concomitant with a significant increase in the peak latency of the population spike. These changes were partially reversible when bilirubin was removed from the incubation fluid. A partially reversible shift to the right of the presynaptic fiber volley/field excitatory postsynaptic potential relationship was interpreted as an expression of a reduction in synaptic activation. A partially reversible shift to the left of the field exitatory postsynaptic potential population spike relationship was interpreted as an expression of increased postsynaptic excitability. In conclusion the in vitro rat hippocampal slice was used successfully to study the effect of bilirubin on neuronal activity. A depressive effect of bilirubin was observed. (Pediatr Res 23: 453456, 1988)
\end{abstract}

\section{Abbreviations}

BSA, bovine serum albumin

ACSF, artificial cerebrospinal fluid

PV/prevolley, presynaptic fiber volley

fEPSP, field excitatory postsynaptic potential

PS, population spike

The neurotoxicity of bilirubin is well recognized (1-5). There is considerable evidence that bilirubin depresses neuronal function. Both auditory and visual evoked responses have been used to follow the course of hyperbilirubinemia (6-8). Studies of the auditory brainstem response have shown reductions of amplitude and increases in peak latencies in jaundiced neonates. These changes are reversed when the serum bilirubin level is lowered $(7,9,10)$. Similar results have been obtained in monkeys and rats during experimentally induced hyperbilirubinemia $(11,12)$. In addition, high bilirubin levels have been shown to suppress electrical activity in rat brain after opening of the blood brain barrier (13). However, the basic neurophysiological mechanism involved in the depressive effect of bilirubin still is unknown.

The in vitro rat hippocampal slice preparation offers a technique to study the mechanisms involved in the activation of a

Received July 27, 1987; accepted December 29, 1987. correspondence Thor Willy Ruud Hansen, M.D., Department of Pediatric Research, Rikshospitalet, N0027 Oslo 1, Norway.

Reprint requests Thor Willy Ruud Hansen, M.D., Department of Pediatric Research, Rikshospitalet, N-0027 Oslo 1, Norway. specific neuronal population (14). The aim herein was to evaluate whether this model might be suitable for analyzing neurophysiological effects of bilirubin. Preliminary observations from some of the experiments have been published $(15,16)$.

\section{METHODS}

Bilirubin and BSA were obtained from Sigma Chemical Co., St. Louis, MO. Other chemicals used were analytical grade.

Young adult male Sprague-Dawley rats were purchased from Dyrlæge Møllegaards Avlslaboratorium, Skensved, Denmark. Their weights at the time of use ranged from $80-350 \mathrm{~g}$ (mean $139 \mathrm{~g})$.

Transverse hippocampal slices were prepared as described by Skrede and Westgaard (14). The slices were placed on a nylon net in an incubation chamber at 30 to $32^{\circ} \mathrm{C}$ and superfused with ACSF of the following composition $(\mathrm{mM}): \mathrm{Na}^{+} 151 ; \mathrm{K}^{+} 5 ; \mathrm{Mg}^{2+}$ $2 ; \mathrm{Ca}^{2+} 2 ; \mathrm{Cl}^{-} 129 ; \mathrm{HCO}_{3}{ }^{-} 26 ; \mathrm{SO}_{4}{ }^{2-} 2 ;$ phosphate 2 ; and glucose 10 , preequilibrated with $95 \% \mathrm{O}_{2} / 5 \% \mathrm{CO}_{2}$ to a $\mathrm{pH}$ of 7.4. In some experiments the calcium concentration in the ACSF was reduced to $1-1.25 \mathrm{mmol} /$ liter. The flow rate was $1 \mathrm{ml} / \mathrm{min}$. A humidified stream of $95 \% \mathrm{O}_{2} / 5 \% \mathrm{CO}_{2}$ was directed over the upper surface of the slices at a rate of approximately $500 \mathrm{ml} /$ min.

After a recovery period of not less than $1 \mathrm{~h}$, platinum-coated tungsten electrodes were placed visually. The stimulating electrode was inserted among the Schaffer collaterals in the stratum radiatum; the recording electrodes were placed in the dendritic field of the stratum radiatum and in the corresponding cell body layer in the stratum pyramidale of the CA1 region (Fig. 1).

The pathways were stimulated using $0.8 \mathrm{~Hz}$ single shock pulses of $0.1 \mathrm{~ms}$ duration. These were delivered by constant voltage stimulators in the initial experiments, later with constant current stimulators. Intensities were adjusted to produce submaximal responses. We measured the amplitude of the PV/prevolley, the slope of the fEPSP, measured as the difference in voltage between two points on the curve, each point having a fixed time relationship to the stimulus, and the amplitude of the PS, as shown in Figure 1. We analyzed and recorded the data on-line with an Apple II+ microcomputer. Analog signals were displayed on an oscilloscope, and photographs of these were taken at intervals for subsequent off-line evaluation.

Bilirubin dissolved in $0.1 \mathrm{~N} \mathrm{NaOH}$ was added to the ACSF to achieve final bilirubin concentrations of 50-1000 $\mu \mathrm{mol} / \mathrm{liter}$. To retard flocculation of bilirubin in these supersaturated solutions, BSA was added in a molar ratio of 1:8 (BSA:bilirubin). Control solutions did not contain bilirubin, but were otherwise identical. All experiments were performed in subdued light, and bilirubincontaining vessels and infusion tubes were wrapped in tin foil.

Alterations in the PV/fEPSP and the fEPSP/PS relationships were studied by recording the responses to different stimulus 


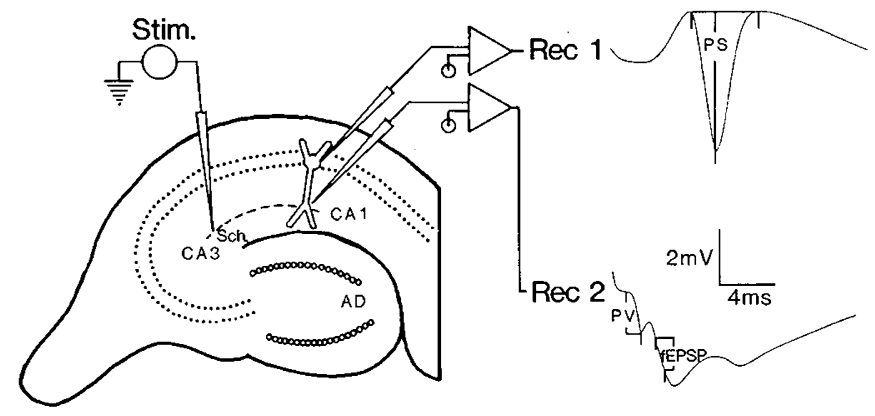

Fig. 1. Schematic illustration of the transverse hippocampal slice. The stimulatory electrode (Stim.) was placed among the Schaffer collaterals $(S c h$.) in the CA3 region. The two recording electrodes were placed in the cell body layer $(\operatorname{Rec} 1)$ and in the dendritic layer $(\operatorname{Rec} 2)$ of the CA1 region. The following parameters were recorded: PV, fEPSP. and PS. $A D$, area dentata.

intensities. Changes in the fEPSP slope and the PS peak latency were calculated as a percentage of the starting values after approximately $60 \mathrm{~min}$ exposure to bilirubin, and again after subsequent exposure to bilirubin-free, BSA-containing ACSF. The statistical significance of these changes was evaluated by calculating the confidence intervals.

\section{RESULTS}

Bilirubin caused a significant reduction in the slope of the fEPSP (mean -30\%, 99.9\% confidence interval -18.2 to -42.6 ; $n=31$ ). Concomitantly the peak latency of the population spike increased significantly (mean $+12 \%, 99.9 \%$ confidence interval 3.2 to $21.4 ; n=23$ ). A typical experiment is illustrated in Figure 2. The changes appeared gradually after intervals of from 10 to $30 \mathrm{~min}$, and increased with time and with the concentration of bilirubin. The lowest concentration of bilirubin associated with such changes was $100 \mu \mathrm{mol} /$ liter. The effects of $100 \mu \mathrm{mol} /$ liter bilirubin were seen under low calcium conditions. In $40 \%$ of the experiments exposure to bilirubin was associated with the appearance of multiple spikes.

The decrease in the fEPSP slope elicited by bilirubin could be partly reversed when the slices were exposed to bilirubin-free ACSF with the same content of BSA (mean $+14 \%$; $95 \%$ confidence interval 1.2 to $27.4 ; n=16$ ). Similarly, the increase in the PS peak latency caused by bilirubin could be reversed by BSA (mean $-11 \%$; $99 \%$ confidence interval -19.9 to $-2.7 ; n=10$ ). Renewed exposure to bilirubin once again reduced the fEPSP slope and increased the PS peak latency (Fig. $3 a$ and $b$ ).

To further investigate the mechanisms underlying the observed depressive effect of bilirubin, the responses to stepwise changes in the stimulus intensity were plotted. The PV/fEPSP curve was shifted to the right and the fEPSP/PS curve was shifted to the left by exposure to bilirubin. These shifts were observed in seven of nine experiments, and could be partly reversed by exposing the slices to bilirubin-free, BSA-containing ACSF. Data from a representative experiment using $1 \mathrm{mmol} /$ liter bilirubin, 125 $\mu \mathrm{mol} /$ liter BSA, and $1 \mathrm{mmol} /$ liter extracellular calcium are shown in Figure $4 a$ and $b$.

\section{DISCUSSION}

The results herein show that a depressive effect of bilirubin is observed and may be studied in the in vitro rat transverse hippocampal slice model. Bilirubin produced a significant reduction in the slope of the fEPSP in rat transverse hippocampal slices, concomitant with a significant increase in the peak latency of the PS. These effects were seen at bilirubin concentrations of as little as $100 \mu \mathrm{mol} / \mathrm{liter}$ in the ACSF after a time span of 10 $30 \mathrm{~min}$. These changes could be partly reversed by BSA. The

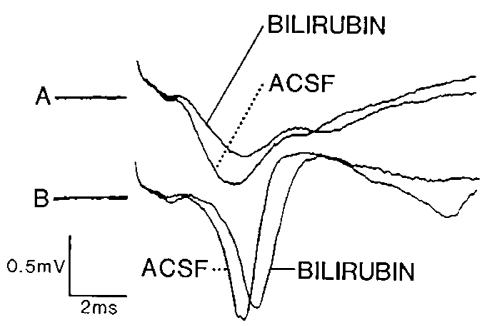

Fig. 2. Effect of bilirubin on extracellular potentials of the CA1 region. Potentials during initial exposure to ACSF and after $55 \mathrm{~min}$ exposure to bilirubin $1000 \mu \mathrm{mol} /$ liter with bovine serum albumin 125 $\mu \mathrm{mol} /$ liter as stabilizer (BILIRUBIN). The bilirubin-induced decrease in the slope of the fEPSP is illustrated in $A$, whereas the concomitant increase in the latency of the PS is shown in $B$.

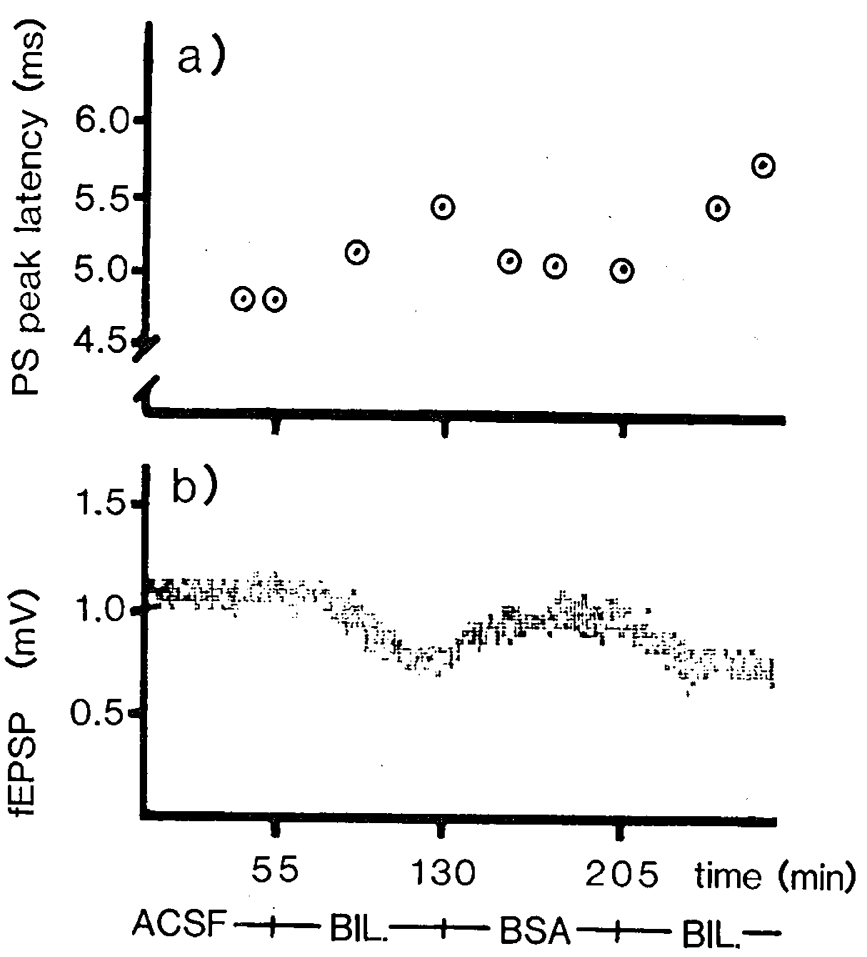

Fig. 3. Reversible effect of bilirubin on population spike peak latency and field EPSP. $a$, changes in the PS peak latency as measured off-line from photographs of the oscilloscope screen. $b$, continuous computer tracing of the field EPSP. $A C S F$, artificial cerebrospinal fluid with 1.25 $\mathrm{mmol} /$ liter $\mathrm{Ca}^{++} . B I L .=500 \mu \mathrm{mol} /$ liter bilirubin with $67.5 \mu \mathrm{mol} / \mathrm{liter}$ BSA in ACSF. $B S A, 67.5 \mu \mathrm{mol} /$ liter BSA in ACSF.

reduction in the slope of the fEPSP together with a shift to the right of the PV/fEPSP curve indicates that bilirubin inhibits synaptic activation. Our data do not permit a definite conclusion on whether this inhibition is due to impaired neurotransmitter release or to an effect on the neuronal membrane.

To the best of our knowledge direct effects of bilirubin on neurotransmitter release have not yet been demonstrated. It has, however, recently been shown that bilirubin inhibits phosphorylation of synapsin $I(17,18)$, which is thought to play a role in neurotransmitter release (19). Also, jaundiced Gunn rats have been found to have a higher concentration of norepinephrine in their hippocampi than their nonicteric (heterozygous) littermates (20). Brann et al. (21) showed that bilirubin inhibits the cAMPstimulated synthesis of dopamine in rat striatal synaptosomes.

The left shift of the fEPSP/PS curve seen during bilirubin exposure indicates an increase in the postsynaptic excitability. The tendency to multiple spikes under these conditions points in the same direction. One possible explanation for this observation might be a reduction in the resting potential. However, it 

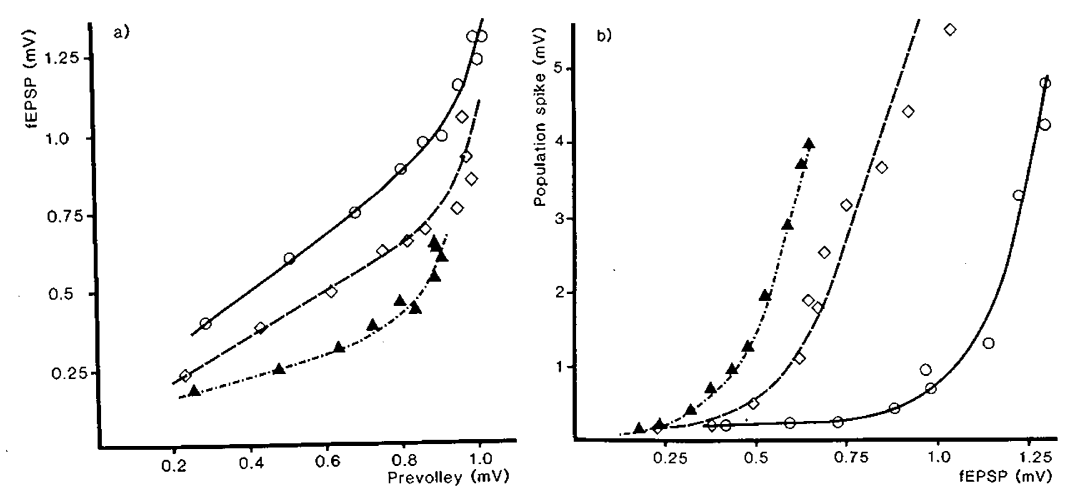

Fig. 4. Effect of bilirubin on PV/prevolley, field EPSP, and population spike at different stimulus strengths. $a$, relationship between the amplitude of the prevolley and the slope of the fEPSP. $b$, relationship between the slope of the fEPSP and the amplitude of the PS. O, during initial exposure to ACSF containing $1 \mathrm{mmol} /$ liter $\mathrm{Ca}^{++} ; \mathbf{\Lambda}, 40 \mathrm{~min}$ after start of exposure to bilirubin $1000 \mu \mathrm{mol} /$ liter with BSA $125 \mu \mathrm{mol} / \mathrm{liter}$ in ACSF. $\diamond, 55 \mathrm{~min}$ after removal of bilirubin solution that was replaced with a solution containing $125 \mu \mathrm{mol} / \mathrm{liter}$ BSA in ACSF. The lines have been drawn by visual approximation.

is known that inhibitory synapses are conserved in transverse hippocampal slices of the thickness used in our experiments $(22$, 23). The increase in postsynaptic excitability observed in our experiments could therefore also be explained on the basis of inhibition of transmission in these inhibitory synapses.

There is a considerable body of evidence indicating that bilirubin may exert an effect on neuronal membranes. Mayor et al. (24) have shown that bilirubin (final concentration $40 \mu \mathrm{mol}$ / liter) induces a rapid depolarization of rat forebrain synaptosomes as reflected by an efflux of previously accumulated ${ }^{3} \mathrm{H}$ tetraphenylphosphonium. BSA in a molar ratio of $1: 1$ to bilirubin could prevent and reverse this effect of bilirubin. Cowger (25) has shown that for periods of up to $4 \mathrm{~h}$ the membranes of bilirubin-exposed cells become increasingly permeable even to such large molecules as enzymes.

In the experiments reported herein we observed effects of bilirubin down to concentrations of $100 \mu \mathrm{mol} / \mathrm{liter}$, but most of the experiments were run at higher concentrations. Although it is unlikely that brain bilirubin concentrations as high as these are attained in the clinical situation, high levels can be found in experimental situations (26-30). Regional variations in brain bilirubin concentrations have been observed, and the hippocampus is among the structures with high bilirubin levels (31). In the basal ganglia of infants dying with hemolytic disease, values of approximately $30-40 \mu \mathrm{mol} /$ liter have been found (32).

Limited information is available concerning regional differences in brain sensitivity to bilirubin toxicity. In the Gunn rat the cerebellum and the Purkinje cells are primarily affected (3336). The behavior of homozygous Gunn rats bears a close resemblance to that of rats with experimental lesions in the hippocampus, also pointing to the hippocampus as an area of higher sensitivity (37).

Some limitations are inherent in the rat hippocampal slice model as used herein. Caution is needed in extrapolating from in vitro findings to the clinical situation. The period of observation is limited to a few hours, and the effects observed may differ from those occuring after several days' exposure in vivo. The presence of albumin as a stabilizer may interfere with the effect of bilirubin. Because of the time element dose-response relationships are difficult to study. Finally, as only one slice can be studied at a time, and as bilirubin is impossible to remove completely once it has been introduced into this system, only one control period is possible per experiment.

In conclusion, we found that bilirubin causes changes in the electrophysiology of rat transverse hippocampal slices, interpreted as evidence of reduced synaptic activation and increased postsynaptic excitability. Our data provide additional evidence that elements of bilirubin neurotoxicity are reversible.

\section{REFERENCES}

1. Byers RK, Paine RS, Crothers B 1955 Extrapyramidal cerebral palsy with hearing loss following erythroblastosis. Pediatrics 15:248-254

2. Perlstein MA 1960 The late clinical syndrome of posticteric encephalopathy. Pediatr Clin North Am 7:665-687

3. Hyman CB, Keaster J, Hanson V, Harris I, Sedgwick R, Wursten H, Wright AR 1969 CNS abnormalities after neonatal hemolytic disease or hyperbilirubinemia. Am J Dis Child 117:395-405

4. Keaster J, Hyman CB, Harris I 1969 Hearing problems subsequent to neonatal hemolytic disease or hyperbilirubinemia. Am J Dis Child 117:406-410

5. Hansen TWR, Bratlid D 1986 Bilirubin and brain toxicity. Acta Paediatr Scand 75:513-522

6. Chisin R, Perlman M, Sohmer H 1979 Cochlear and brain stem responses in hearing loss following neonatal hyperbilirubinemia. Ann Otol 88:352-357

7. Perlman M, Fainmesser P, Sohmer H, Tamari H, Wax Y, Pevsmer B 1983 Auditory nerve-brainstem evoked responses in hyperbilirubinemic neonates. Pediatrics 72:658-664

8. McPehrson DL, Ghosh B, Huxtable RF 1984 Visual evoked potentials in the newborn. J Perinatol 4:2-8

9. Nwaesei CG, Van Aerde J, Boyden M, Perlman M 1984 Changes in auditory brainstem responses in hyperbilirubinemic infants before and after exchange transfusion. Pediatrics 74:800-803

10. Anagnostakis D, Berdoussi $\mathrm{H}$, Fotindis N 1983 Auditory brainstem response in severely jaundiced newborn: effect of exchange transfusion. Biol Neonate 44:376A

11. Ahlfors CE, Shoemaker CT, Bennett SH, Ellis WG 1984 Bilirubin associated abnormalities of the auditory brainstem response in an infant Rhesus monkey model. Pediatr Res 18:308A

12. Karplus M, Lee C, Oh W, Cashore WJ 1986 The effects of bilirubin on brain stem auditory evoked responses in rats. Pediatr Res 20:351A

13. Wennberg RP, Hance AJ 1986 Experimental bilirubin encephalopathy: importance of total bilirubin, protein binding, and blood brain barrier. Pediatr Res 20:789-792

14. Skrede KK, Westgaard RH 1971 The transverse hippocampal slice: a well defined cortical structure maintained in vitro. Brain Res 35:589-593

15. Hansen TWR, Paulsen O, Gjerstad L, Bratlid D 1985 Bilirubin reversibly reduces synaptic transmission in rat hippocampal slices. Pediatr Res 19:1082A

16. Hansen TWR, Paulsen O, Gjerstad L, Bratlid D 1987 Effects of bilirubin on field potentials in rat hippocampal slices. In: Stern L, Oh W, Friis-Hansen B (eds) Physiologic Foundations of Perinatal Care, Vol 2. Elsevier Science Publishing Co., New York, pp 311-319

17. Hansen TWR, Walaas SI, Bratlid D, Greengard P 1986 Effects of bilirubin on phosphorylation of synapsin I. Pediatr Res 20:462A

18. Hansen TWR, Walaas SI, Bratlid D 1988 Bilirubin decreases phosphorylation of synapsin I, a synaptic vesicle-associated neuronal phosphoprotein, in intact synaptosomes from rat cerebral cortex. Pediatr Res 23:219-223

19. Greengard P, De Camilli P 1982 Protein phosphorylation in neurons. In: Schotland DL (ed) Disorders of the Motor Unit. Houghton Mifflin Professional Publishers, Boston, pp 441-460

20. Swenson RM, Jew JY 1982 Learning deficits and brain monoamines in rats with congenital hyperbilirubinemia. Exp Neurol 76:447-456

21. Brann BS, Cashore WJ, Patrick R, Oh W 1985 In vitro effect of bilirubin on dopamine synthesis in adult rat brain synaptosomes. Pediatr Res 19:335A

22. Dingledine R, Gjerstad L 1979 Penicillin blocks hippocampal IPSPs, unmasking prolonged EPSPs. Brain Res 168:205-209

23. Dingledine R, Gjerstad L 1980 Reduced inhibition during epileptiform activity in the in vitro hippocampal slice. J Physiol 305:297-313 
24. Mayor F Jr, Diez-Guerra J, Valdivieso F, Mayor F 1986 Effect of bilirubin on the membrane potential of rat brain synaptosomes. J Neurochem 47:363369

25. Cowger M 1971 Mechanism of bilirubin toxicity on tissue culture cells: factors that affect toxicity, reversibility by albumin, and comparison with other respiratory poisons and surfactants. Biochem Med 5:1-16

26. Morphis L, Constantopoulos A, Matsaniotis N, Papaphilis A 1982 Bilirubininduced modulation of cerebral protein phosphorylation in neonate rabbits in vivo. Science $218 ; 156-158$

27. Bratlid D, Cashore WJ, Brubakk A, Oh W 1984 Bilirubin displacement by sulfisoxazole. Entry of unbound bilirubin into the brain. Pediatr Res 18:150A

28. Bratlid D, Cashore WJ, Oh W 1983 Effect of serum hyperosmolality on opening of blood-brain barrier for bilirubin in rat brain. Pediatrics 71:909-912

29. Bratlid D, Cashore WJ, Oh W 1984 Effect of acidosis on bilirubin deposition in rat brain. Pediatrics 73:431-434

30. Levine RL, Fredericks WR, Rapoport SI 1985 Clearance of bilirubin from rat brain after reversible osmotic opening of the blood-brain barrier. Pediatr Res 19:1040-1043

31. Levine RL, Fredericks WR, Rapoport SI 1982 Entry of bilirubin into the brain due to opening of the blood-brain barrier. Pediatrics 69:255-259

32. Claireaux AE, Cole PG, Lathe GH 1953 Icterus of the brain in the newborn. Lancet 2:1226-1230

33. Sawasaki Y, Yamada N, Nakajima H 1976 Developmental features of cerebellar hypoplasia and brain bilirubin levels in a mutant (Gunn) rat with hereditary hyperbilirubinemia. J Neurochem 27:577-583

34. Mikoshiba K, Kohsaka S, Takamatsu K, Tsukada Y 1980 Cerebellar hypoplasia in the Gunn rat with hereditary hyperbilirubinemia: immunohistochemical and neurochemical studies. J Neurochem 35:1309-1318

35. Aono S, Sato H, Semba R, Kashiwamata S, Eng LF 1985 Studies on the cerebellar 50,000 dalton protein associated with cerebellar hypoplasia in jaundiced Gunn rats: its identity with glial fibrillary acidic protein as evidenced by the improved immunoblotting method. J Neurochem 44:18771884

36. O'Callaghan JP, Miller DB 1985 Cerebellar hypoplasia in the Gunn rat is associated with quantitative changes in neurotypic and gliotypic proteins. $\mathbf{J}$ Pharmacol Exp Ther 234:522-533

37. Butcher RE, Stutz RM, Berry HK 1971 Behavioral abnormalities in rats with neonatal jaundice. Am J Ment Defic 75:755-759 